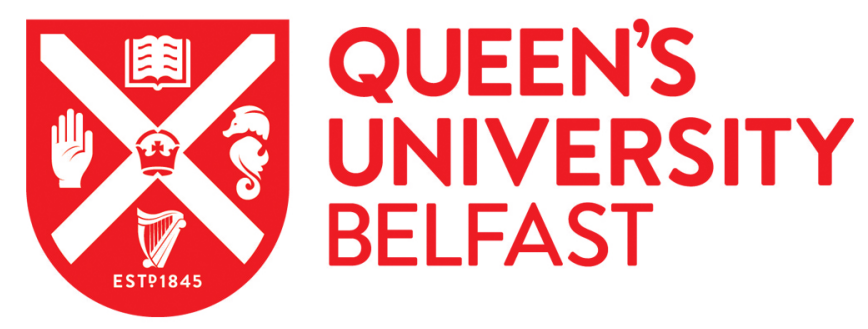

\title{
Combined Analysis of Gamma-H2AX/53BP1 Foci and Caspase Activation in Lymphocyte Subsets Detects Recent and More Remote Radiation Exposures
}

Horn, S., Barnard, S., Brady, D., Prise, K. M., \& Rothkamm, K. (2013). Combined Analysis of Gamma-

H2AX/53BP1 Foci and Caspase Activation in Lymphocyte Subsets Detects Recent and More Remote Radiation Exposures. Radiation Research, 180(6), 603-609. https://doi.org/10.1667/RR13342.1

Published in:

Radiation Research

Document Version:

Publisher's PDF, also known as Version of record

Queen's University Belfast - Research Portal:

Link to publication record in Queen's University Belfast Research Portal

Publisher rights

(c) 2013 Radiation Research Society.

\section{General rights}

Copyright for the publications made accessible via the Queen's University Belfast Research Portal is retained by the author(s) and / or other copyright owners and it is a condition of accessing these publications that users recognise and abide by the legal requirements associated with these rights.

Take down policy

The Research Portal is Queen's institutional repository that provides access to Queen's research output. Every effort has been made to ensure that content in the Research Portal does not infringe any person's rights, or applicable UK laws. If you discover content in the

Research Portal that you believe breaches copyright or violates any law, please contact openaccess@qub.ac.uk. 


\title{
Combined Analysis of Gamma-H2AX/53BP1 Foci and Caspase Activation in Lymphocyte Subsets Detects Recent and More Remote Radiation Exposures
}

\author{
Simon Horn, ${ }^{a, b, 1}$ Stephen Barnard, ${ }^{a}$ Darren Brady ${ }^{b}$ Kevin M. Prise ${ }^{b}$ and Kai Rothkamm ${ }^{a}$ \\ a Public Health England Centre for Radiation, Chemical and Environmental Hazards, Chilton, Didcot, Oxon, OX11 ORQ, United Kingdom; and \\ ${ }^{b}$ Centre for Cancer Research and Cell Biology, Queen's University Belfast, 97 Lisburn Road, Belfast BT9 7BL, United Kingdom
}

Horn, S., Barnard, S., Brady, D., Prise, K. M. and Rothkamm, K. Combined Analysis of Gamma-H2AX/53BP1 Foci and Caspase Activation in Lymphocyte Subsets Detects Recent and More Remote Radiation Exposures. Radiat. Res. 180, 603-609 (2013).

Analysis of gamma-H2AX foci in blood lymphocytes is a promising approach for rapid dose estimation to support patient triage after a radiation accident but has one major drawback: the rapid decline of foci levels post-exposure cause major uncertainties in situations where the exact timing between exposure and blood sampling is unknown. To address this issue, radiation-induced apoptosis (RIA) in lymphocytes was investigated using fluorogenic inhibitors of caspases (FLICA) as an independent biomarker for radiation exposure, which may complement the gamma-H2AX assay. Ex vivo X-irradiated peripheral blood lymphocytes from 17 volunteers showed dose- and time-dependent increases in radiation-induced apoptosis over the first 3 days after exposure, albeit with considerable interindividual variation. Comparison with gamma-H2AX and 53BP1 foci counts suggested an inverse correlation between numbers of residual foci and radiation-induced apoptosis in lymphocytes at $24 \mathrm{~h}$ postirradiation $(P=0.007)$. In T-helper (CD4), T-cytotoxic (CD8) and B-cells (CD19), some significant differences in radiation induced DSBs or apoptosis were observed, however no correlation between foci and apoptosis in lymphocyte subsets was observed at $24 \mathrm{~h}$ postirradiation. While gammaH2AX and 53BP1 foci were rapidly induced and then repaired after exposure, radiation-induced apoptosis did not become apparent until $24 \mathrm{~h}$ after exposure. Data from six volunteers with different $e x$ vivo doses and post-exposure times were used to test the capability of the combined assay. Results show that simultaneous analysis of gamma-H2AX and radiation-induced apoptosis may provide a rapid and more accurate triage tool in situations where the delay between exposure and blood sampling is unknown compared to gamma-H2AX alone. This combined approach may improve the accuracy of dose estimations in cases where

\footnotetext{
${ }^{1}$ Address for correspondence: Centre for Cancer Research and Cell Biology, Queen's University Belfast, 97 Lisburn Road, Belfast BT9 7BL, UK; e-mail: sjh.horn@gmail.com.
}

blood sampling is performed days after the radiation exposure. ๑ 2013 by Radiation Research Society

\section{INTRODUCTION}

In a radiation emergency, many potentially exposed individuals may not be triaged until $24 \mathrm{~h}$ post exposure at the earliest. It is clear that biomarkers whose radiation signature remain elevated or are induced $24 \mathrm{~h}$ post exposure are needed to aid triage. As the peripheral blood lymphocyte is the cell type of choice for biological dosimetry $(1-4)$, detection of proteins involved in senescence or cell cycle arrest do not make good candidates for analysis due to the noncycling nature of lymphocytes. Lymphocytes however are highly radiosensitive (despite being $\mathrm{G}_{0}$ cells) and readily undergo cell death by apoptosis after exposure to ionizing radiation $(5,6)$. This makes detecting radiation-induced apoptosis (RIA) in lymphocytes a good candidate assay for biological dosimetry (7).

Apoptosis is the process of programmed cell death, inducible by both external and internal signaling pathways or a combination of both (8). After exposure to ionizing radiation, induced mutations (9), misrepair (6) and/or unrepaired damage to the DNA [especially unrepaired double-strand breaks (DSBs)] (10) can severely disrupt cell homeostasis, prompting proapoptotic signaling resulting in DNA fragmentation (11), cell shrinkage (12) and ultimately phagocytosis (13) of what remains. Apoptosis destroys the cell from within in a controlled manner to minimize disruption to the surrounding tissue (14). Ionizing radiations proficiency at cell killing are highlighted by there extensive use in the treatment of cancer; however this proficiency and its mutagenic potential also pose a serious health risk to the general public.

The major players at the end of the apoptosis pathways are the caspases $(15,16)$. These cysteine proteases can be split into roughly two groups, initiator and effectors. Initiator caspases $(8,9$ and 10) are a part of the signaling 

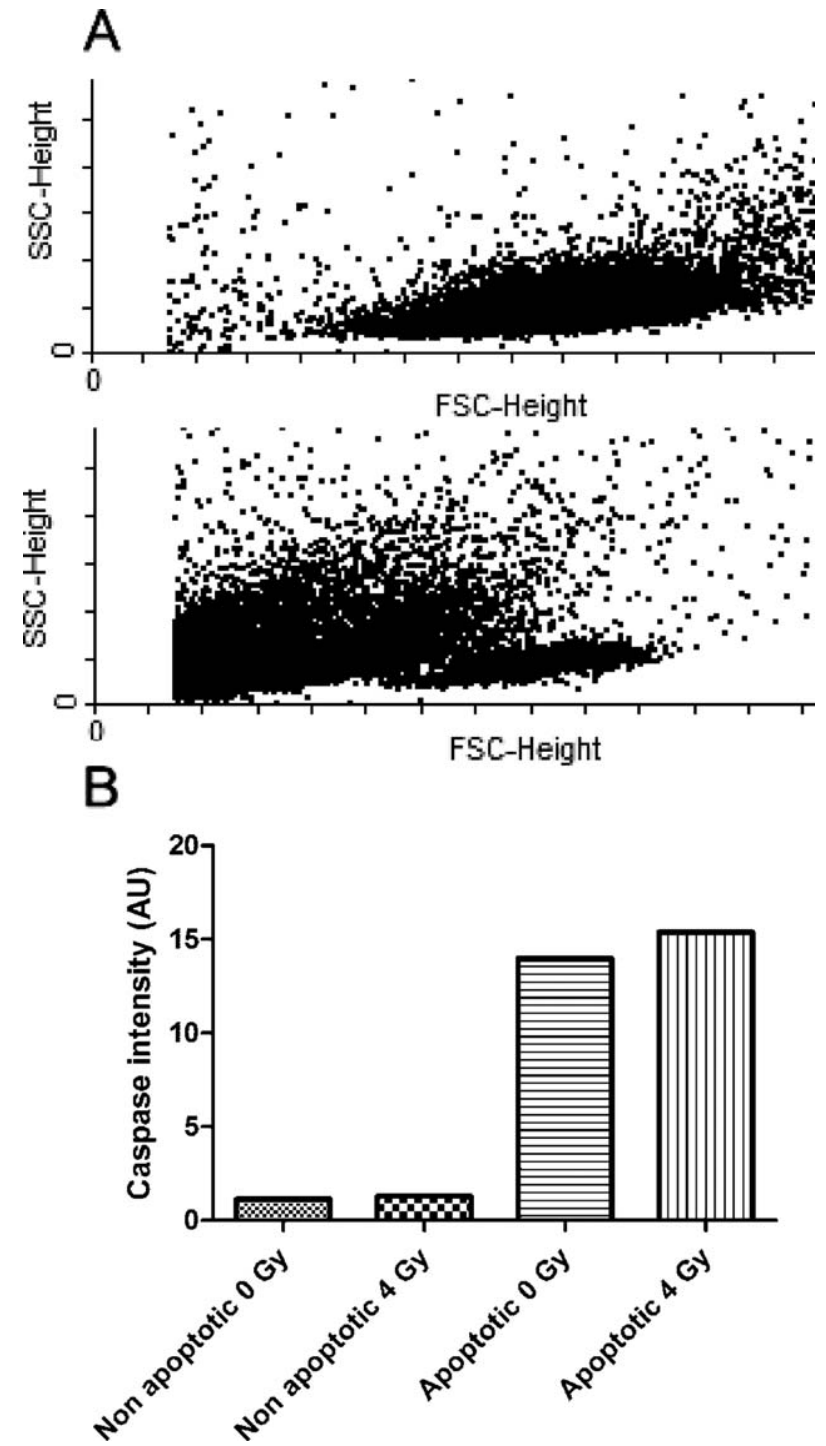

FIG. 1. Panel A: Dot plot showing forward scatter vs. side scatter of sham-irradiated (top) and 4 Gy irradiated lymphocytes $24 \mathrm{~h}$ postirradiation (bottom). Panel B: Shows caspase intensity levels in sham-irradiated or 4 Gy irradiated apoptotic or nonapoptotic lymphocytes.

cascade which communicates to the effector caspases $(3,6$ and 7) (17). Effector caspases, especially caspase 3 are responsible for cleaving a large number of targets, which results in controlled cellular break down (i.e., structural proteins, DNase zymogens and DNA repair proteins) (18, 19).

To help validate caspase induction as a marker of ionizing radiation established radiation biomarkers, gamma-H2AX and 53BP1 (20), have been used to correlate double-strand break induction and repair with radiation-induced apoptosis in lymphocytes from healthy donors. The use of the gamma$\mathrm{H} 2 \mathrm{AX}$ and 53BP1 foci assay is an emerging tool in the field of biological dosimetry. However, unlike established biological dosimetry assays such as the dicentric assay (21), dose estimations based on foci counts are sensitive to time after exposure to a greater degree than the dicentric assay (hours vs. months) resulting in rapidly diminishing sensitivity $24 \mathrm{~h}$ after exposure. To offset this inherent weakness, combining the foci assay with a biomarker whose peak signal is not reached until many hours or days after initial exposure would allow for greater sensitivity after $24 \mathrm{~h}$ and better define (and potentially reduce) any uncertainties in dose estimations. Furthermore, certain lymphocyte subsets, specifically B-cells, tend to display greater levels of radiation-induced apoptosis than T-cells (22) and it has been suggested radiation induced DSBs are heterogeneous between subsets (23). If so then it may be more advantageous, to analyze the most radiosensitive subset rather than the entire lymphocyte population when trying to detect low doses of radiation.

\section{METHODS}

\section{Blood Collection, Lymphocyte Isolation and Irradiation}

After obtaining ethical approvals from the Berkshire Research Ethics Committee (ref. no. 09/H0505/87) and Queen's University Belfast school ethics board (ref. no. 12.13v2) and informed consent from donors, peripheral blood from healthy donors (no previous medical radiation exposures, aged 24-65) was collected into EDTA vacutainer tubes. Blood was mixed with an equal volume of PBS and lymphocytes were isolated using Histopaque-1077 solution (SigmaAldrich) and resuspended in minimum essential medium (supplemented with $10 \%$ fetal calf serum, $1 \%$ L-glutamine and $1 \%$ penicillin/ streptomycin) at $37^{\circ} \mathrm{C}$. Cells were irradiated with different doses of copper- and aluminum-filtered $250 \mathrm{kVp} \mathrm{X}$ rays at $1.7 \mathrm{~Gy} / \mathrm{min}$, with controls sham irradiated. Cells were incubated at $37^{\circ} \mathrm{C}, 5 \% \mathrm{CO}_{2}$ in a humidified atmosphere for up to 3 days. Independent samples of lymphocytes were used for gamma-H2AX and 53BP1 foci assays, 53BP1 and CD marker assays and radiation-induced apoptosis caspase assays with each assay having their own separate controls.

\section{Fixation, Staining and Scoring of Gamma-H2AX and 53BPI Foci}

Cells were spotted onto glass Superfrost Plus slides (VWR International) at a concentration of $\sim 1 \times 10^{6}$ cells $/ \mathrm{ml}$, fixed using $2 \%$ formaldehyde in PBS for 10 min, washed in PBS, permeabilized using $0.5 \%$ (v/v) Triton-X in PBS for 10 min then washed in PBS. Blocking was achieved using $1 \%(\mathrm{w} / \mathrm{v})$ bovine serum albumin (BSA) in PBS for $30 \mathrm{~min}$. Cells were then incubated with a combination of 1:500 mouse monoclonal anti-gamma-H2AX antibody (Abcam) and 1:400 rabbit polyclonal anti-53BP1 antibody (Bethyl Laboratories) in $1 \% \mathrm{BSA}$ in PBS for $1 \mathrm{~h}$ at room temperature. Cells were then washed in 1\% BSA in PBS, incubated in 1:200 anti-mouse AlexaFluor 488 conjugated antibody (Invitrogen), 1:200 anti-rabbit tetramethylrodamineisoiocyanate (TRITC) conjugated antibody (Jackson ImmunoResearch) and $200 \mathrm{ng} / \mathrm{ml} \mathrm{4',6-diamidino-2-phenylindole} \mathrm{(DAPI)} \mathrm{in}$ $1 \% \mathrm{BSA}$ and PBS for $1 \mathrm{~h}$ at room temperature, washed in PBS, dried, mounted with a cover slip using Vectashield ${ }^{\circledR}$ (Vector Laboratories) and sealed using nail polish. Gamma-H2AX and 53BP1 foci were scored by eye with a Nikon Eclipse TE200 epifluorescence microscope using a $100 \times$ objective with 1.3 NA. Fifty cells were scored for each data point.

Fixation, Staining and Scoring of 53BP1 Foci in Lymphocyte Subsets

The above methods were used for 53BP1 foci analysis with the exception of the anti-gamma-H2AX antibody being replaced with 1:200 mouse monoclonal anti-CD4, CD8 or CD19 antibody (Abcam). 

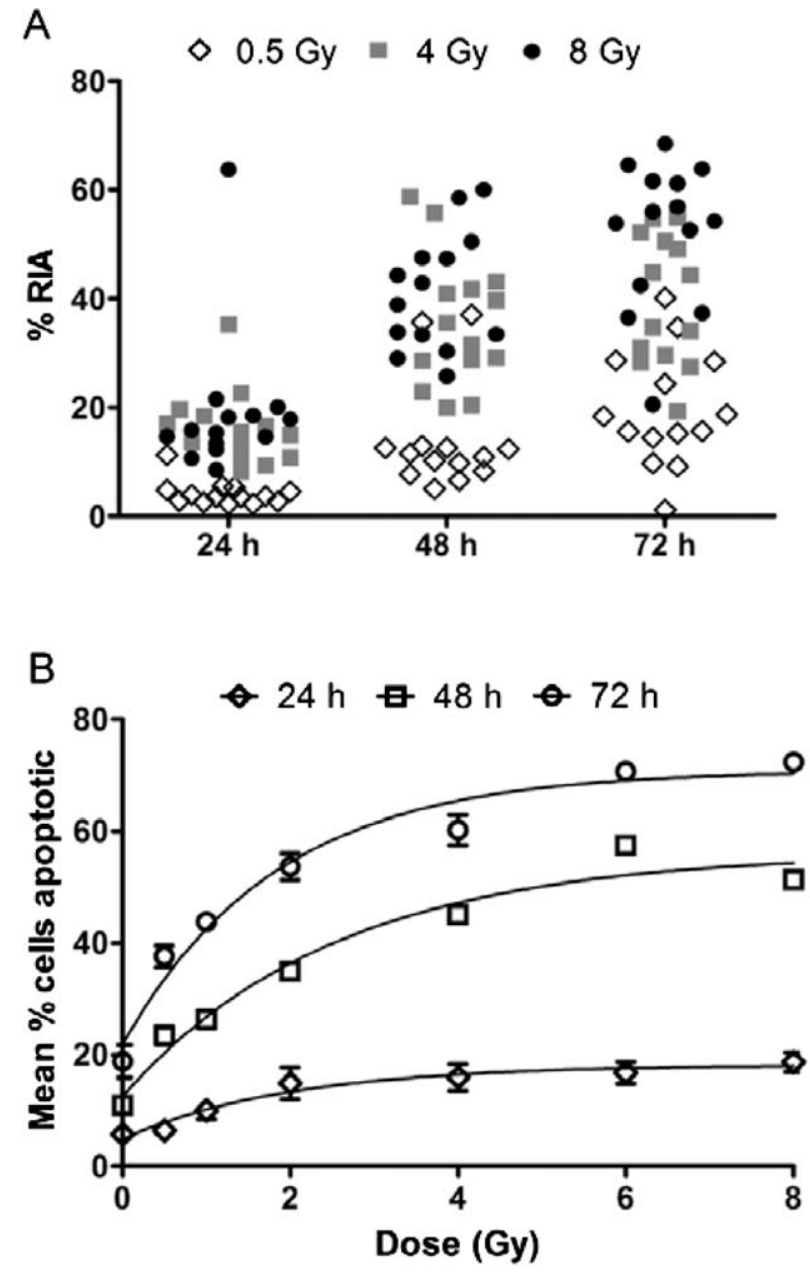

C

\begin{tabular}{|c|c|c|c|}
\hline & 0.5 vs. 4 Gy & 0.5 vs. 8 Gy & 4 vs. 8 Gy \\
\hline $24 \mathrm{~h}$ & $\mathbf{0 . 0 0 2}$ & $\mathbf{0 . 0 1 9}$ & $\mathbf{0 . 0 0 1}$ \\
\hline $48 \mathrm{~h}$ & 0.817 & $\mathbf{0 . 0 4 3}$ & 0.051 \\
\hline $72 \mathrm{~h}$ & 0.24 & $\mathbf{0 . 0 4 5}$ & 0.064 \\
\hline
\end{tabular}

FIG. 2. Panel A: Radiation-induced apoptosis (RIA) in ex vivo irradiated lymphocytes expressed as a percentage, apoptosis is shown for 24, 48 and $72 \mathrm{~h}$ after exposure. Panel B: One phase exponential association fits to the data sets at 24,48 and $72 \mathrm{~h}$, shows good agreement with the actual data points. Error bars represent the standard error between the 17 donors $(0,0.54$ and $8 \mathrm{~Gy})$ or 3 donors $(1,2$ and 6 Gy). Panel C: Spearman rank order correlation $P$ values (with significant values highlighted in bold, $P<0.05$ ) indicate some degree of correlation in radiation-induced apoptosis in these donors.

Fixation, Staining and Measurements of Caspase Intensity for Radiation-Induced Apoptosis

Caspase activation was detected using the FLICA Poly Caspase kit (Immunochemistry Technologies) as per the manufacturer's instructions and briefly repeated here. Isolated peripheral blood lymphocytes were incubated with 1:150 FLICA for $1 \mathrm{~h}$ prior to fixation at a concentration of $5 \times 10^{5}$ cells per ml. Cells were then fixed using $2 \%$ formaldehyde in PBS for 10 min, washed in PBS, permeabilized using $0.5 \%(\mathrm{v} / \mathrm{v})$ Triton-X in PBS for 10 min then washed in PBS. Blocking was achieved using 1\% (w/v) bovine serum albumin (BSA) in PBS for $30 \mathrm{~min}$. Cells were then incubated with 1:200 mouse monoclonal antiCD4, CD8, CD19 antibody (Abcam) in 1\% BSA and PBS for $1 \mathrm{~h}$ at room temperature or no antibody. Cells were then washed in $1 \% \mathrm{BSA}$ in PBS, incubated in 1:200 anti-mouse AlexaFluor 660 conjugated antibody (Invitrogen), or no secondary antibody if no primary was applied. Samples stained only with FLICA were then stained with propidium iodide. Nonapoptotic lymphocytes were selected based on previously known values for their forward scatter and side scatter, a constant DNA signal (propidium iodide intensity) and being caspase negative (Fig. 1), with a minimum of 5,000 cells measured for each experiment. Apoptotic cells were identified as having a smaller forward scatter (apoptotic cells shrink), greater side scatter (increasing complexity of cellular content due to organelle breakdown) and being caspase positive. Cells labeled with FLICA and CD antibodies were additionally selected based on the intensity of the CD marker.

\section{RESULTS}

In ex vivo irradiated lymphocytes, there were three factors governing radiation-induced apoptosis from X-ray exposure; the dose received; culture time postirradiation; and interindividual variation (Fig. 2A). Increasing dose and subsequent culture time increased radiation-induced apoptosis levels, with radiation-induced apoptosis following a one-phase exponential function with respect to dose between 24-72 h postirradiation (Fig. 2B). From Fig. 2B, it is clear that 0.5 Gy was far more efficient per unit dose at inducing radiation-induced apoptosis than $4 \mathrm{~Gy}$ and both of these more efficient than $8 \mathrm{~Gy}$. At $24 \mathrm{~h}$, a strong correlation was observed where individuals whose lymphocytes had the lowest radiation-induced apoptosis at $0.5 \mathrm{~Gy}$ also had the lowest radiation-induced apoptosis at 4 and 8 Gy (Fig. 2C). At 48 and $72 \mathrm{~h}$ this was less obvious, with either no or borderline correlation observed.

53BP1 foci counts in T-helper, T-cytotoxic or B-cells (CD4, CD8 and CD19, respectively) lymphocytes from 14 healthy donors revealed a significant correlation in foci numbers between T-helper/T-cytotoxic and T-helper/B-cells at $0.5 \mathrm{~h}$ after $0.5 \mathrm{~Gy}$ exposure (Fig. 3A), with those with the lowest foci numbers in T-helper lymphocytes also possessing lower foci numbers in T-cytotoxic and B-cells, this however was not seen at $24 \mathrm{~h}$ after 0.5 Gy exposure (Fig. 3B). No significant variation in foci counts for the lymphocytes subsets were observed at $0.5 \mathrm{~h}$ after 0.5 Gy exposure, however at $24 \mathrm{~h}$ after $4 \mathrm{~Gy}$ exposure residual 53BP1 foci numbers were significantly lower in B-cells compared to $\mathrm{T}$ helper and T-cytotoxic (Fig. 3C). The general trend for radiation-induced apoptosis in lymphocyte subsets was $\mathrm{T}$ helper $<$ T-cytotoxic $<$ B-cells, although T-cytotoxic $<$ Bcells was reversed at $48 \mathrm{~h}$ after 4 Gy exposure (Fig. 3D), with radiation-induced apoptosis in T-cytotoxic and B-cells significantly elevated against T-helper lymphocytes at $48 \mathrm{~h}$ after 4 Gy exposure. No correlation between foci and percentage of radiation-induced apoptosis was observed in any lymphocyte subset $24 \mathrm{~h}$ after 4 Gy exposure.

By utilizing a combination of foci scoring and apoptosis detection in lymphocytes, different irradiation time points 

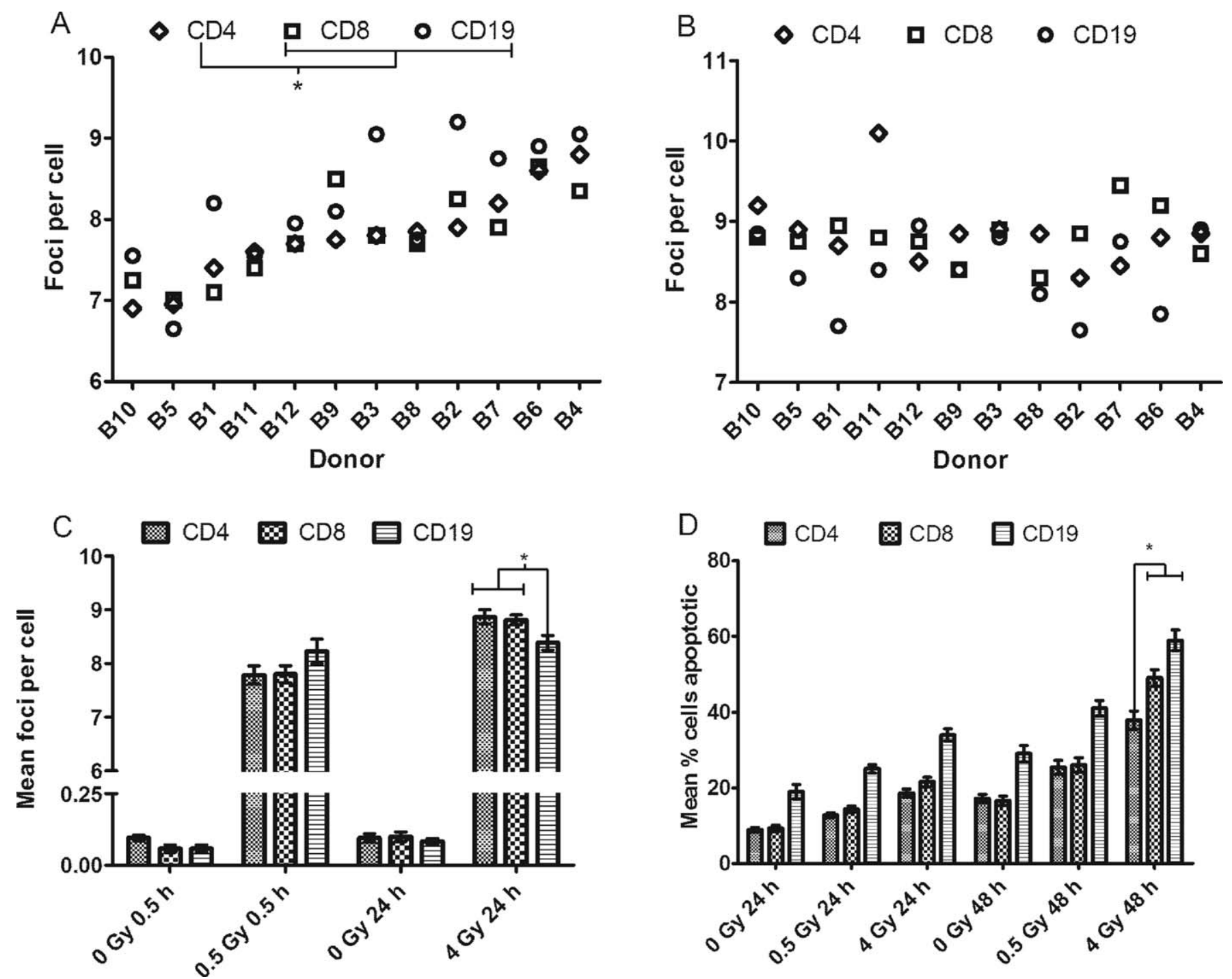

FIG. 3. 53BP1 foci numbers in lymphocyte subsets in ex vivo irradiated lymphocytes. Background corrected foci counts in 12 healthy donors are shown for $0.5 \mathrm{~h}$ after 0.5 Gy exposure (panel A) and $24 \mathrm{~h}$ after 4 Gy exposure (panel B). Panels C and D: Correlation analysis between foci numbers in individual donors subsets was performed using Spearman rank order analysis with significant correlations $(P<0.05)$ indicated with *. Means foci counts (panel C) and means percentage (\%) cells apoptotic (panel D) between subsets were compared using independent student's $t$ test with significant differences $(P<0.05)$ indicated with *.

can be easily distinguished by the lack of apoptosis induction soon after exposure. For dose and time points that produce similar foci counts ( 0.5 Gy 0.5 h/4 Gy 24 h), markedly different levels of radiation-induced apoptosis are observed within lymphocytes (Fig. 4A). Comparison of gamma-H2AX and 53BP1 foci counts against radiationinduced apoptosis in the lymphocytes of 14 healthy donors highlighted an inverse correlation of increased foci numbers with lower levels of radiation-induced apoptosis 24 post exposure (Fig. 4B).

\section{DISCUSSION}

Our findings show that radiation-induced apoptosis in $e x$ vivo $\mathrm{X}$-irradiated lymphocytes is most efficient at lower doses, with higher doses not inducing the same level of apoptosis per unit dose. Caspase saturation starts to appear at $<10$ Gy reinforcing the notion of lymphocyte acute radiosensitivity compared to several other tissues, which display latent late-responding toxicity $(24,25)$. In terms of correlating radiation-induced apoptosis within donors, at $24 \mathrm{~h}$ there appeared to be a strong correlation between dose and radiation-induced apoptosis in individuals. It has been observed in clinical radiotherapy samples that patients with the greatest levels of residual gamma-H2AX (26) and lower radiation-induced apoptosis (27) tended to suffer from more severe late normal tissue effects. However this was the only time point where individuals with the greatest radiation-induced apoptosis for $0.5 \mathrm{~Gy}$ also showed the greatest levels of radiation-induced apoptosis for 4 and 8 


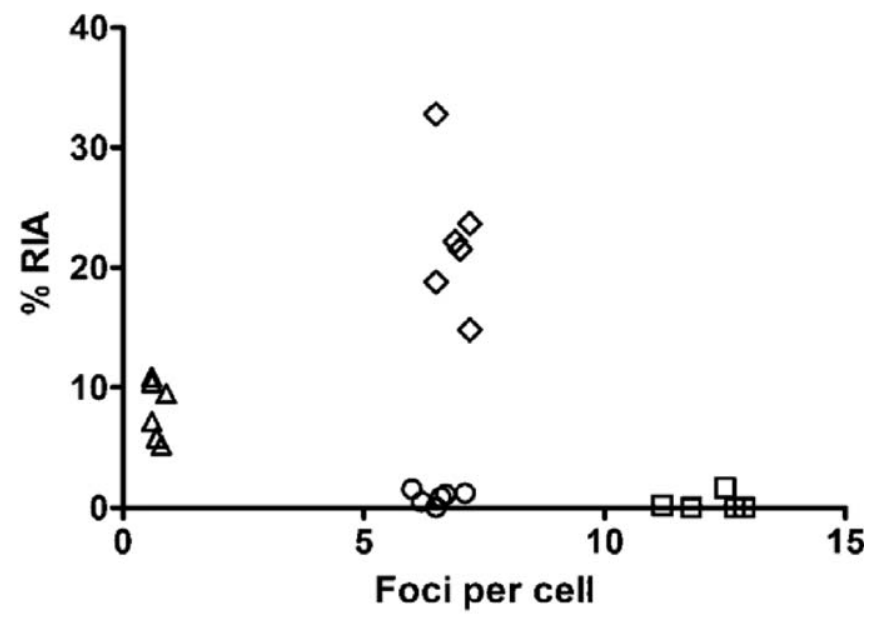

B

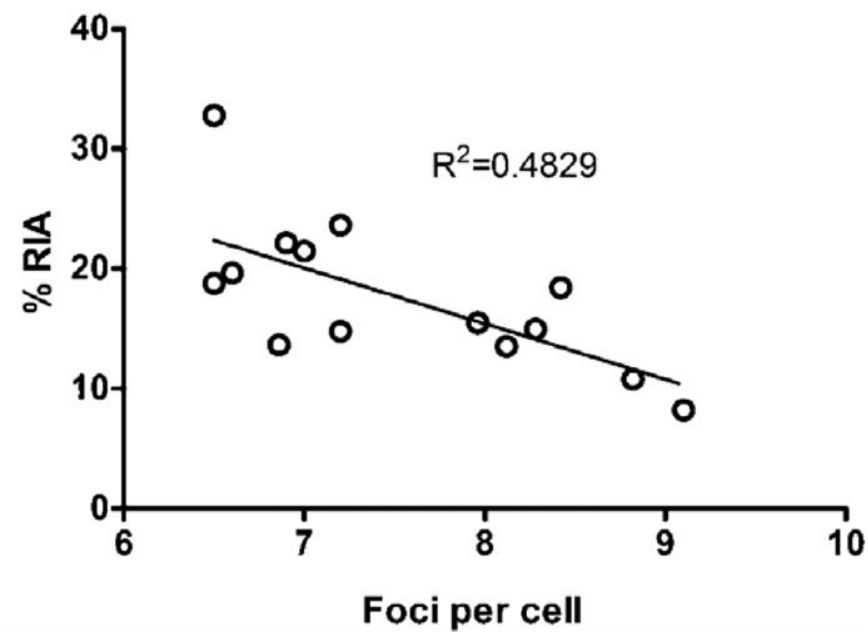

FIG. 4. Foci per cell vs. percentage radiation-induced apoptosis (\%RIA) in ex vivo irradiated lymphocytes. Panel A: Six healthy donors, $1 \mathrm{~h}$ after $0.5 \mathrm{~Gy}$ exposure $(\mathrm{O}) \mathrm{h}$ after $4 \mathrm{~Gy}$ exposure $(\square) ; 24$ $\mathrm{h}$ after 0.5 Gy exposure $(\triangle)$; and $24 \mathrm{~h}$ after 4 Gy exposure $(\diamond)$. Data is corrected for spontaneous foci and apoptosis at all time points investigated. Panel B: Linear correlation between foci and radiationinduced apoptosis at $24 \mathrm{~h}$ post exposure to $4 \mathrm{~Gy}$ in 14 healthy donors (including the 6 donors from Fig. 3A).

Gy, with the lack of a strong correlation at 48 and $72 \mathrm{~h}$ coupled with variable spontaneous (28) and radiationinduced apoptosis makes drawing conclusions difficult. When comparing our own radiation-induced apoptosis to those previously reported it becomes clear that a significant level of assay-to-assay variation is observed. Forty-eight hours after a 3 Gy irradiation, Belloni et al. reported a lymphocyte viability of $70 \%$ using trypan blue occlusion and $50 \%$ using a marker of mitochondria polarization (6). Schmitz et al. observed stark differences in lymphocyte subset (CD4, CD8 and CD19) radiationinduced apoptosis using an annexin V reporter (29). Variations in the amount of apoptosis for each assay could be due to variability and the stage at which they detect a cell of being apoptotic. For example increases in p53 levels would be seen in the early stages of apoptosis, whereas the loss of membrane integrity is considered a late event. How cells are cultured once extracted from the donor will also have implications on spontaneous apoptosis in lymphocytes (whether culture alters lymphocyte radiosensitivity is less well understood).

Radiation-induced apoptosis in lymphocyte subsets displayed a general trend, CD4 < CD8 < CD19 (29), with the greatest distinction (and only significant one) observed after 4 Gy. While CD19 positive cells show greatly increased spontaneous apoptosis and with spontaneous apoptosis levels practically zero in vivo (unpublished data), it cannot be dismissed that culturing the lymphocytes in an ex vivo environment may alter their radiation response. The lack of correlation between the radiosensitivity of lymphocyte subsets within individual patients at either 24 or $48 \mathrm{~h}$ post exposure highlights the variability in intra-donor radiation-induced apoptosis. It has been shown (30) that ex vivo irradiated lymphocytes failed to predict acute toxicity in radiotherapy patients, only late toxicity was predicted. Cultured lymphocytes in media will not be exposed to the same external signaling pathways that cells in an irradiated individual would be. Acute phase proteins involved in the radiation inflammatory response such as Creactive protein and serum amyloid A (31) are secreted from the liver in response to interleukin signaling after exposure to ionizing radiation. Further work is needed to compare radiation-induced apoptosis in vivo to the ex vivo radiationinduced apoptosis observed within this work to help better understand the rate of induction and turnover of apoptotic lymphocytes in vivo.

The lack of correlation between 53BP1 foci and radiationinduced apoptosis in lymphocyte subsets (but not the total lymphocyte population) suggests that DSBs do not correlate with radiation-induced apoptosis in the subsets of healthy donors selected here. This suggests that while 53BP1 foci formation (32) and radiation-induced apoptosis (33) increase with ionizing radiation dose, it is known DSBs induce apoptosis through the activation of p53 through ATM phosphorylation $(34,35)$. Therefore, maybe radiationinduced apoptosis at least partially independent of DSB formation. However, the lack of correlation between 53BP1 foci and apoptosis, could also be the result of too few radioresistant or sensitive donors in the general population to be adequately detected in our small sample size.

By utilizing a combination of foci scoring and apoptosis detection in lymphocytes, different irradiation time points can be easily distinguished by the lack of apoptosis induction soon after exposure. For dose and time points that produce similar foci counts $(0.5$ Gy $0.5 \mathrm{~h} / 4$ Gy $24 \mathrm{~h}$ ), knowledge of when the exposure took place is needed to help differentiate the dose and reduce the degree of uncertainty that would be present in any dose estimate. However the lack of apoptotic lymphocytes in one and not the other would points towards a more distant exposure time 
in the sample containing apoptotic cells. Samples containing cells with low foci counts but high levels of apoptosis would again suggest a large exposure has taken place perhaps days ago.

A potential advantage of measuring the number of circulating apoptotic lymphocytes as opposed to total lymphocyte counts or other serum markers is the greater sensitivity and reduced uncertainty in any dose estimations. In past radiation emergency scenarios, total lymphocyte counts have provided dosimetric information on radiation casualties (36). However due to the large intervariation and intravariation between individuals dose estimates carry with them large uncertainties with only high total-body doses generally detectable (37). Rather than measure total cells, determining the number of apoptotic (or even necrotic) lymphocytes may allow dose estimates down to low doses $(<500 \mathrm{mGy})$ if the number of background circulating apoptotic lymphocytes is low.

\section{CONCLUSION}

T-helper, T-cytotoxic and B-cells do not show consistent and strongly significantly different radiation responses from each other, for biodosimetry this makes analyzing individual subsets unnecessary. However, using caspase activation and inhibition as a biomarker of radiation exposure has shown promising results. When coupled with foci scoring a more accurate estimation of time and extent of exposure can be made. The sensitivity of the caspase assay highlights the usefulness of quantifying the number of radiation induced apoptotic lymphocytes, in conjunction with gamma-H2AX foci, for biological dosimetry. If confirmed in vivo, this may potentially allow for dose estimations of greater accuracy with fewer uncertainties when compared to those estimates made by each assay alone or currently used hematological measurements, such as total lymphocyte counts.

\section{ACKNOWLEDGMENTS}

This work was supported by the National Institute for Health Research and the Health Protection Agency (PN1725/107036). DB is supported by a clinical fellowship from the Friends of the Cancer Centre.

Received: January 25, 2013; accepted: September 10, 2013; published online: November 12, 2013

\section{REFERENCES}

1. Edwards AA, Lloyd DC, Purrott RJ. Radiation induced chromosome aberrations and the Poisson distribution. Radiat Environ Biophys 1979; 16:89-100.

2. Duran A, Barquinero JF, Caballín MR, Ribas M, Puig P, Egozcue J, Barrios L. Suitability of FISH painting techniques for the detection of partial-body irradiations for biological dosimetry. Radiat Res 2002; 157:461-468.

3. Vaurijoux A, Gruel G, Pouzoulet F, Grégoire E, Martin C, RochLefèvre $S$, et al. Strategy for population triage based on dicentric analysis. Radiat Res 2009; 171:541-548.
4. Kanda R, Minamihisamatsu M, Hayata I. Dynamic analysis of chromosome aberrations in three victims of the Tokai-mura criticality accident. Int J Radiat Biol 2002; 78:857-862.

5. Belloni P, Meschini R, Czene S, Harms-Ringdahl M, Palitti F. Studies on radiation-induced apoptosis in G0 human lymphocytes. Int J Radiat Biol 2005; 81:587-599.

6. Belloni P, Meschini R, Lewinska D, Palitti F. Apoptosis preferentially eliminates irradiated g0 human lymphocytes bearing dicentric chromosomes. Radiat Res 2008; 169:181-187.

7. Menz R, Andres R, Larsson B, Ozsahin M, Trott K, Crompton NE. Biological dosimetry: the potential use of radiation-induced apoptosis in human T-lymphocytes. Radiat Environ Biophys 1997; 36:175-181.

8. Fulda S, Debatin K. Extrinsic versus intrinsic apoptosis pathways in anticancer chemotherapy. Oncogene 2006, 25:4798-4811.

9. Zhang D, Mott JL, Farrar P, Ryerse JS, Chang S, Stevens M, et al. Mitochondrial DNA mutations activate the mitochondrial apoptotic pathway and cause dilated cardiomyopathy. Cardiovasc Res 2003; 57:147-157.

10. Rothkamm K, Löbrich M. Misrepair of radiation-induced DNA double-strand breaks and its relevance for tumorigenesis and cancer treatment (review). Int J Oncol 2002; 21:433-440.

11. Nagata S. Apoptotic DNA fragmentation. Exp Cell Res 2000; 256:12-18.

12. Bortner CD, Cidlowski JA. A necessary role for cell shrinkage in apoptosis. Biochem Pharmacol 1998; 56:1549-1559.

13. Savill J. Recognition and phagocytosis of cells undergoing apoptosis. Br Med Bull 1997; 53:491-508.

14. Kuwano K, Hara N. Signal transduction pathways of apoptosis and inflammation induced by the tumor necrosis factor receptor family. Am J Respir Cell Mol Biol 2000; 22:147-149.

15. Bidère N, Senik A. Caspase-independent apoptotic pathways in $\mathrm{T}$ lymphocytes: a minireview. Apoptosis 2001; 6:371-375.

16. Cohen GM. Caspases: the executioners of apoptosis. Biochem J 1997; 326 (Pt 1):1-16.

17. Bao Q, Shi Y. Apoptosome: a platform for the activation of initiator caspases. Cell Death Differ 2007; 14:56-65.

18. Rehm M, Huber HJ, Dussmann H, Prehn JHM. Systems analysis of effector caspase activation and its control by X-linked inhibitor of apoptosis protein. EMBO J 2006; 25:4338-4349.

19. Slee EA, Adrain C, Martin SJ. Executioner caspase-3, -6, and -7 perform distinct, non-redundant roles during the demolition phase of apoptosis. J Biol Chem 2001; 276:7320-7326.

20. Horn S, Barnard S, Rothkamm K. Gamma-H2AX-based dose estimation for whole and partial body radiation exposure. PlosOne 10.1371/journal.pone.0025113:.

21. Romm H, Oestreicher U, Kulka U. Cytogenetic damage analysed by the dicentric assay. Ann Ist Super Sanita 2009; 45:251-259.

22. Wilkins RC, Wilkinson D, Maharaj HP, Bellier PV, Cybulski MB, McLean JRN. Differential apoptotic response to ionizing radiation in subpopulations of human white blood cells. Mutat Res 2002; 513:27-36.

23. Andrievski A, Wilkins RC. The response of gamma-H2AX in human lymphocytes and lymphocytes subsets measured in whole blood cultures. Int J Radiat Biol 2009; 85:369-376.

24. Stryker JA. Science to practice: why is the liver a radiosensitive organ? Radiology 2007; 242:1-2.

25. Heidenreich PA, Kapoor JR. Radiation induced heart disease: systemic disorders in heart disease. Heart 2009; 95:252-258.

26. Chua MLK, Somaiah N, A'Hern R, Davies S, Gothard L, Yarnold $\mathrm{J}$, et al. Residual DNA and chromosomal damage in ex vivo irradiated blood lymphocytes correlated with late normal tissue response to breast radiotherapy. Radiother Oncol 2011; 99:362366 .

27. Schnarr K, Boreham D, Sathya J, Julian J, Dayes IS. Radiation- 
induced lymphocyte apoptosis to predict radiation therapy late toxicity in prostate cancer patients. Int J Radiat Oncol Biol Phys 2009; 74:1424-1430.

28. Orlova NV, Smirnova SG, Zamulaeva IA, Andreev VG, Riabchenko NI, Saenko AS. Apoptosis of peripheral lymphocytes of healthy donors and patients with laryngeal neoplasms after gammairradiation in vitro. Radiats Biol Radioecol 2001; 41:366-372.

29. Schmitz A, Bayer J, Déchamps N, Thomas G. Intrinsic susceptibility to radiation-induced apoptosis of human lymphocyte subpopulations. Int J Radiat Oncol Biol Phys 2003; 57:769-778.

30. Ozsahin M, Crompton NEA, Gourgou S, Kramar A, Li L, Shi Y, et al. CD4 and CD8 T-lymphocyte apoptosis can predict radiationinduced late toxicity: a prospective study in 399 patients. Clin Cancer Res 2005; 11:7426-7433.

31. Ossetrova N, Sandgren D, Blakely W. C-reactive protein and serum amyloid A as early-phase and prognostic indicators of acute radiation exposure in nonhuman primate total-body irradiation model. Radiat Meas 2011; 46:1019-1024.

32. Burdak-Rothkamm S, Rothkamm K, Prise KM. ATM acts downstream of ATR in the DNA damage response signaling of bystander cells. Cancer Res 2008; 68:7059-7065.

33. Horn S, Rothkamm K. Candidate protein biomarkers as rapid indicators of radiation exposure. Radiat Meas 2011; 46:903-906.

34. Banin S, Moyal L, Shieh S, Taya Y, Anderson CW, Chessa L, et al. Enhanced phosphorylation of p53 by ATM in response to DNA damage. Science 1998; 281:1674-1677.

35. Canman CE, Lim DS, Cimprich KA, Taya Y, Tamai K, Sakaguchi $\mathrm{K}$, et al. Activation of the ATM kinase by ionizing radiation and phosphorylation of p53. Science 1998; 281:1677-1679.

36. Bertho JM, Roy L, Souidi M, Benderitter M, Gueguen Y, Lataillade JJ, et al. New biological indicators to evaluate and monitor radiation-induced damage: an accident case report. Radiat Res 2008; 169:543-550.

37. Blakely WF, Ossetrova NI, Whitnall MH, Sandgren DJ, Krivokrysenko VI, Shakhov A, et al. Multiple parameter radiation injury assessment using a nonhuman primate radiation modelbiodosimetry applications. Health Phys 2010; 98:153-159. 